\title{
Postoperative analgesic efficacy of Fascia Iliaca Block versus Peng Block for Total Hip Arthroplasty
}

\author{
Nicoletta Podavini M.D. - Ospedale Santa Corona - Pietra Ligure - Italy
}

Nowadays Total Hip Arthroplasty is the most frequent surgery in orthopedic and traumatology departments for femur fractures and primary arthrosis. The Fascia lliaca Block (FIB) is used in THA to control post-surgery pain.

Recently a new block named Peng (Pericapsular Nerve Group) Block has been introduced for the analgesia in this surgery.

\section{METHOD}

I treated 18 patients, with prior consent, randomly split into 2 groups: 9 with FIB and 9 with Peng block.

Before the surgery, I practiced to all patients Subarachnoid $\begin{array}{llll}\text { Anesthesia with } \quad \text { Bupivacaine } & 0.5 \% & 12 \mathrm{mg} \text {. }\end{array}$ At the end, I injected to all the patients under ultrasound guidance Ropivacaine $0.5 \% 30 \mathrm{ml}$. + Desamethason $8 \mathrm{mg} .$, : in the Fascia lliaca for the FIB group, and below the ileopsoas muscle's tendon, at the ileopectineal eminence, for the Peng group.

Post-surgery treatment:

Paracetamol $1 \mathrm{gr} \times 3$ / Die ; Ketorolac if NRS $>4$ and Morphine 5 $\mathrm{mg}$ if $\mathrm{NRS}>6$.

\section{RESULTS}

We did NRS at rest and in movement after 30 and 60 minutes, then every $8 \mathrm{~h}$ for the first day, then every $24 \mathrm{~h}$ for the next 2 days. It showed a better control of pain in the PENG.

Only 2 patients treated with FIB requested the rescue drug Ketrolac.

None of the 18 patients needed Morphine during the 3 days.

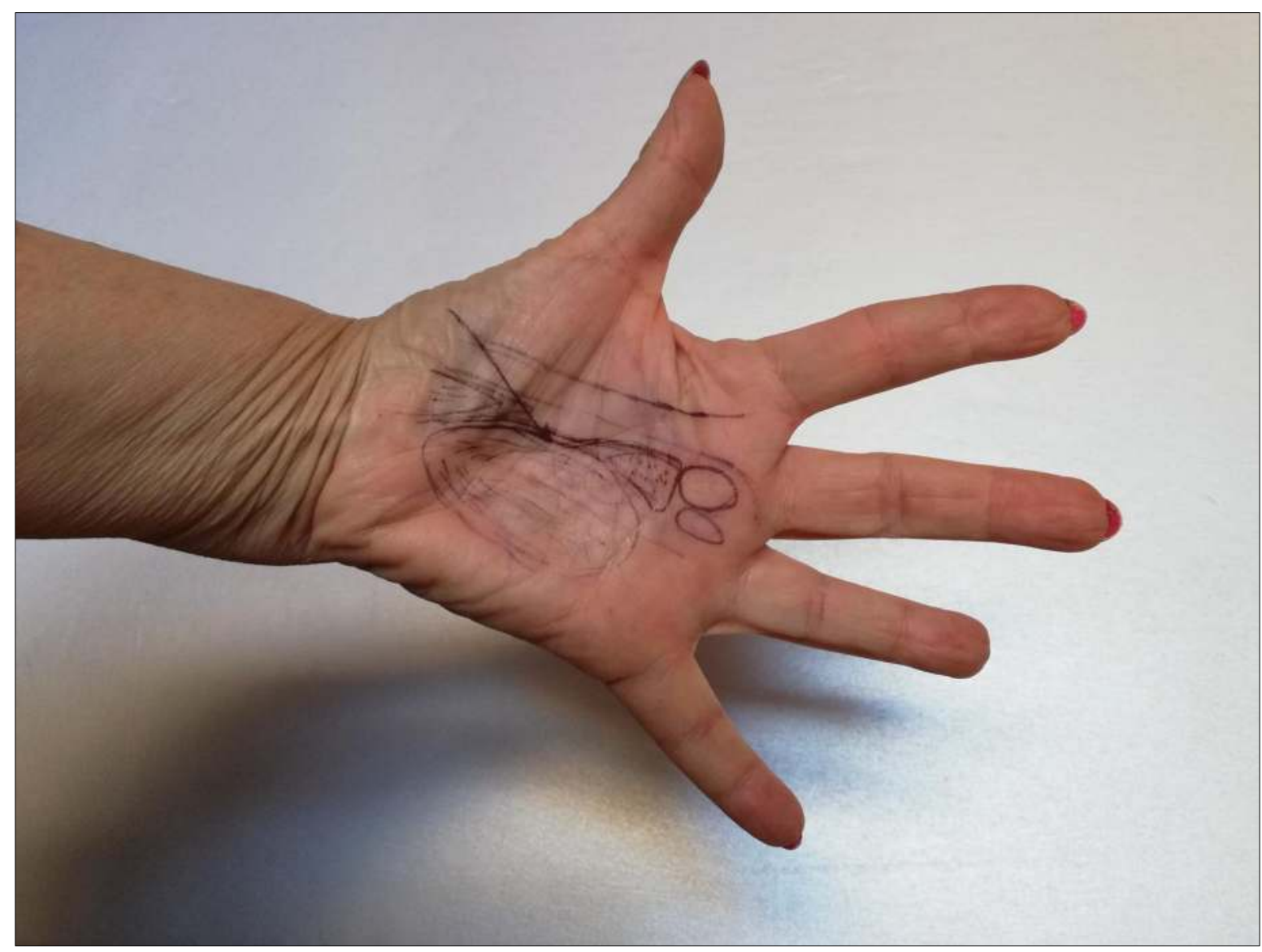

\section{CONCLUSIONS}

The application of FIB and Peng Block showed excellent pain control and avoided the use of Morphine. The new Peng has proved to perform better for pain relief. These results must be confirmed by further studies.
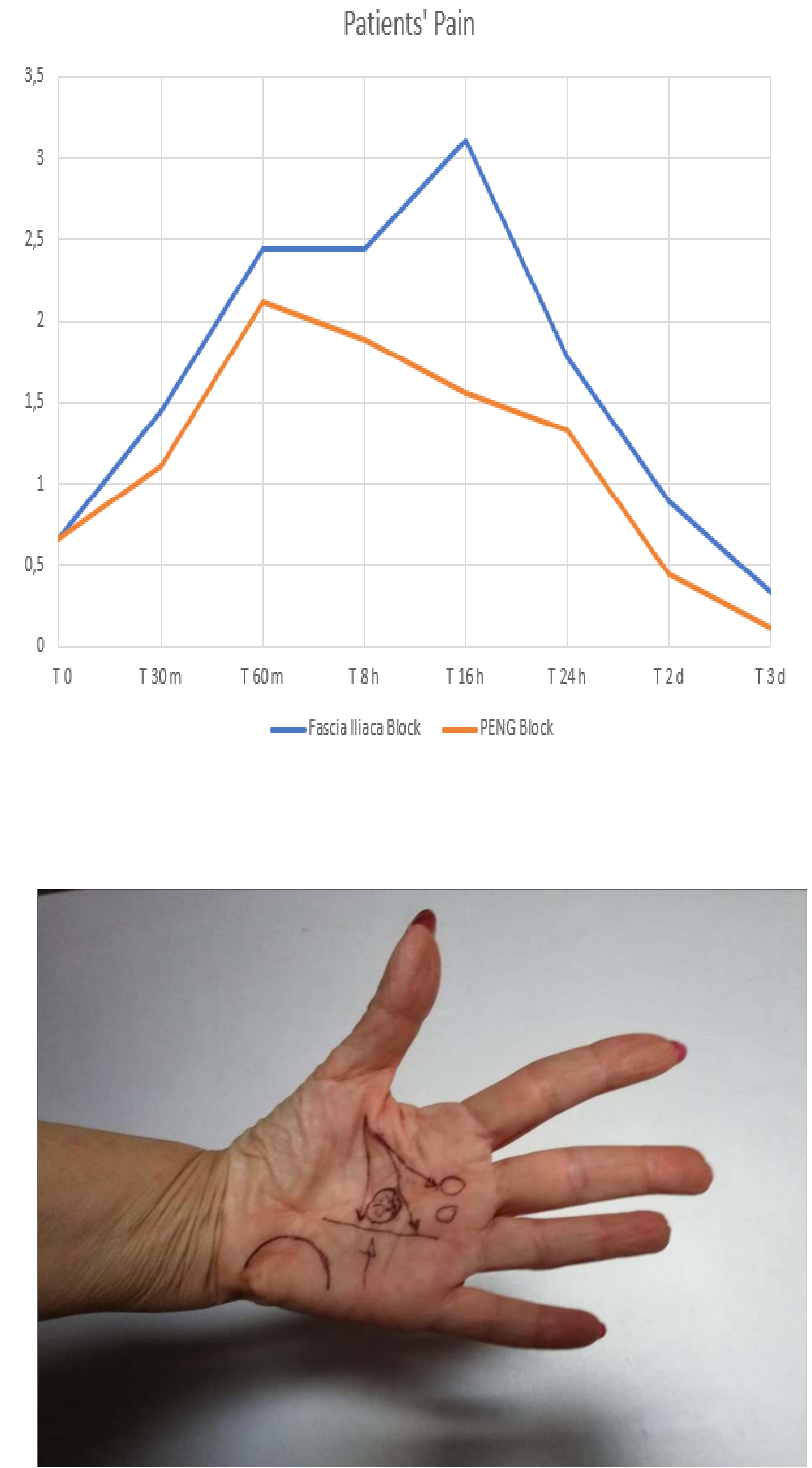

Copyright $@ 2019$ - Nicoletta Podavini M.D. n.podavini@gmail .com 